\title{
O Corpo Insone (C.I.): do sono como dispositivo, da insônia como gestus
}

\author{
Potyguara Alencar dos Santos ${ }^{1}$ \\ Carolline Rocha Parente de Pinho ${ }^{2}$ \\ Mônica da Silva Araújo3 \\ Universidade Federal do Piauí
}

Resumo: No artigo, entremeamos o assunto dos "distúrbios do sono" entre dois paradigmas: aquele que escrutina as epistemes médicas e suas ansiedades de época inspirado nas formulações foucaultianas e aquele de uma "antropologia subtrativa" que pense os gestus volitivos de "desparecer de si” dos Corpos Insones (C. I.). Quem são os formuladores contemporâneos das intervenções prático-conceituais contra o "problema da insônia" e comos os próprios insones, desde seus mundos da vida em claro refletidos, leem a insistência noturna dos seus estados de vigília? O contraponto entre conhecimento médico e experiências sociossubjetivas significadas é feito pela aproximação dos conteúdos técnicos produzidos pelos corpos clínicos do Laboratório do Sono da Universidade de São Paulo (Incor/USP) e do Instituto do Sono de um lado e, do outro, as expressões de três biografias que tentaram significar suas vivências de noites em claro ante o nosso coletivo de pesquisadores.

Palavras-chave: insônia; positividade biopolítica; mundos da vida; antropologia subtrativa.

\footnotetext{
${ }^{1}$ Possui doutorado e mestrado em Antropologia Social pela Universidade de Brasília (UnB). Foi secretário do Laboratório de Estudos da Globalização e do Desenvolvimento (LEG - UnB) e membro do Laboratório e Grupo de Estudos em Relações Interétnicas (LAGERI - UnB). Atualmente é pesquisador PNPD/Capes do Programa de Pós-Graduação em Antropologia da Universidade Federal do Piauí (PPGAnt/UFPI).

2 Possui graduação em Psicologia pela Faculdade Integral Diferencial-FACID (2016). Psicóloga no Centro de Atenção Psicossocial I (CAPS I-Miguel Alves-PI) desde 2016. Especialista em Docência do Ensino Superior (2016). É mestranda do Programa de Pós-Graduação em Antropologia da Universidade Federal do Piaú (PPPGAnt/UFPI).

3 Possui graduação em História pela Universidade Federal Fluminense (1998), mestrado em História Social pela Universidade Federal do Rio de Janeiro (2002), doutorado em Antropologia Social pelo Programa de Pós-Graduação em Antropologia Social do Museu Nacional (PPGAS/UFRJ, 2011) e Pós-Doutorado pelo Programa de Pós-Graduação em Antropologia da Universidade Federal da Paraíba. Professora Adjunta I do Departamento de Ciências Sociais (UFPI) e do Programa de Pós-Graduação em Antropologia (PPGAnt-UFPI).
} 


\title{
The Insomnia Body (I. B.): \\ from sleep as a device, from insomnia as a gestus
}

\begin{abstract}
Abstact: In the article, we interweave the subject of "sleep disturbances" between two paradigms: the one that scrutinizes medical epistems and their period anxieties inspired by Foucaultian formulations and that of a "subtractive anthropology" that thinks of the volitional gestures of "disappearing from oneself" of the Insomniac Bodies (CI). Who are the contemporary formulators of practical-conceptual interventions against the "problem of insomnia," and how do the insomniacs themselves, from their clearly reflected worlds of life, read the nocturnal insistence of their waking states? The counterpoint between medical knowledge and meaningful socio-subjective experiences is made by the approximation of the technical contents produced by the clinical bodies of the Sleep Laboratory of the University of São Paulo (Incor / USP) and the Sleep Institute on one side and, on the other, expressions of three biographies that tried to signify their experiences of clear nights before our collective of researchers.
\end{abstract}

Keywords: insomnia; biopolitical positivity; worlds of life; subtractive anthropology.

\section{El cuerpo del insomnio (C.I.): del sueño como dispositivo, del insomnio como gesto}

\begin{abstract}
Resumen: En el artículo, entrelazamos el tema de las "alteraciones del sueño" entre dos paradigmas: el que analiza los epistemas médicos y sus ansiedades menstruales inspiradas en las formulaciones foucaultianas y el de una "antropología sustractiva" que piensa en los gestos volitivos de "desaparecer de uno mismo" de los cuerpos insomnes (CI). ¿Quiénes son los formuladores contemporáneos de intervenciones prácticas-conceptuales contra el "problema del insomnio" y cómo los mismos insomnes, desde sus mundos de vida claramente reflejados, leen la insistencia nocturna de sus estados de vigilia? El contrapunto entre el conocimiento médico y las experiencias socio-subjetivas significativas se realiza mediante la aproximación de los contenidos técnicos producidos por los órganos clínicos del Laboratorio del Sueño de la Universidad de São Paulo (Incor / USP) y el Instituto del Sueño por un lado y, por el otro, expresiones de tres biografías que intentaron significar sus experiencias de noches despejadas ante nuestro colectivo de investigadores.
\end{abstract}

Palabras clave: insomnio; positividad biopolítica; mundos de la vida; antropología sustractiva. 
(...) mesmo se você conseguisse adormecer tão profundamente que nenhum choque, nenhum chamado, nenhuma queimação pudesse despertá-lo, ainda haveria aquele olho, seu olho, que nunca se fecha, que nunca adormece.

Georges PEREC, Un homme qui dort (1967: 117, tradução nossa)

Se formos ver pela nossa definição de saúde e doença, segundo a Organização Mundial de Saúde, a saúde é o bem-estar físico, mental, espiritual e mais alguma outra coisa. Se eu perguntar aqui quem tem tudo isso ao mesmo tempo, ninguém vai levantar a mão. Então, como nós temos uma visão muito idealizada de saúde, todo mundo fica o quê? Doente. Então, a gente tem uma visão naturalmente errada: então todo mundo tá doente, todo mundo deprimido, pressão alta, refluxos.

Prof. Dr. Geraldo LORENZI-FILHO,

Médico Pneumologista especialista em Medicina do Sono, representante do Laboratório do Sono (Incor/USP) 4

$\mathrm{N}$

osso projeto de reflexão tem sua necessária origem na aproximação de duas proposições de pesquisa, algo que pode ser lido como uma problematização feita pela regência de duas questões: pergunta-se, em um primeiro plano, quais são as intervenções médicas e terapêuticas mais comuns que discernem e interpretam os motivos para os chamados "problemas contemporâneos com o sono" - de cujo fenômeno resultante mais conhecido e divulgado é a insônia -, e, em um segundo momento, indaga quais são os gestus centrados nas interpretações dos "mundos da vida" (life-worlds) dos indivíduos insones -, claro, interpretações essas feitas por eles sobre suas próprias experiências de "noites em claro" (SCHÜTZ e LUCKMANN, 1972; SCHÜTZ, 1979) -, que resultaria na manifestação rotineira de manter um corpo em vigília.

Em diante da segunda ordem de problematização da qual lançamos mão, a hipótese de valor contraintuitivo que pomos à mostra é a de que o Corpo Insone (C.I.) mais do que não conseguir dormir, de alguma forma "não o quer, assim não o deseja”. O porquê de esses indivíduos acometidos pela insônia aparentemente não querem entregar seus corpos ao sono ritual, socialmente prescrito e organicamente reparador do final do dia ganha uma resposta no contínuo do texto, quando questionamos se tal atitude ativa de não dormir não poderia estar relacionada àquilo que David Le Breton qualificou como um gestus programado de "desaparecer de si” (LE BRETON, 2018) e que filósofo brasileiro Vladmir Safatle chamou, em Patologias do Social (2018), de uma "antropologia subtrativa" (SAFATLE, 2018); qual seja: nossas ações furtivas muito contemporâneas de escapar às obrigações dos nossos sujeitos e subjetividades de desempenho - essas geralmente operadas à luz do dia e sob os signo de identidades sociais prepostas (HAN,

4 Trecho transcrito da comunicação de título "Tu roncas, eu acordo, ninguém dorme”, realizada no evento TEDx Talks São Paulo Salon (Theme: Futuro da Saúde), em 12 de maio de 2018, Memorial da América Latina, São Paulo (SP). 
2015; GAUCHET, 2004) -, se deslocando consciente e inconscientemente na direção da conquista de ociosidades ou vivenciais ocupacionais não laborais ou, no mínimo, não sobredeterminadas por ordenamentos jurídicos e de poder.

Essas duas questões - aquela que indaga sobre a positividade biopolítica do cuidado com o sono e a outra que se pergunta pelas positividades corporais individuais de permanecer em estado de vigília - são postas em diante de duas naturezas de dados apreciados. Nos tópicos seguintes trabalharemos com duas mostras de informações, de cuja justificativa para suas escolhas detalharemos na sequência: produziremos uma leitura do conteúdo dos procedimentos clínicos de três fontes que constituem aquilo que chamamos, em parte inspirados em Foucault (1966), de "epistemes do sono"; são elas: algumas produções científicas movimentadas pelo Laboratório do Sono da Universidade de São Paulo (Incor/USP) e pelo Instituto do Sono, que no Brasil são as duas mais conhecidas instituições vertedoras de conhecimentos sobre o assunto. Delas, referenciamos, rastreamos e analisamos excertos de artigos, notícias e seminários que procuram qualificar os fatores que gerariam a insônia e/ou a interrupção de um ideado "sono normal".

Com a análise intensiva dos conteúdos desse primeiro acúmulo de informações, chamamos a atenção para o adensamento de um campo de especialidades médicas focalizadas na expectativa de realização da "noite perfeita de sono". Destacamos que tais conhecimentos atuam reforçando um apurado de procedimentos que inspiram a formulação de algo como manuais biomecânicos e ergométricos de cuidados que incidem ativamente sobre o indivíduo e suas responsabilidades com os seus próprios "desligamentos". Atitude terapêutica que acaba pulsionando obrigações em sujeitos e subjetividades de desempenho já insatisfeitos e/ou frustrados com as realizações das suas trajetórias diurnas, principalmente com os seus projetos laborais; pelos quais já foram, via de regra, neuronal e muscularmente minados.

A segunda concentração de dados diz respeito propriamente ao conteúdo expressivo de três narrativas biográficas, relatos de sujeitos de idades, ocupações laborais e contextos sociais distintos em torno de suas experiências com a insônia. Esses interlocutores foram escolhidos por estarem à procura de tratamentos adequados para os seus casos, tendo sido acessados em coletivos virtuais que acompanham sites especializados no assunto e também descobertos entre a rede de amigos e conhecidos dos membros do grupo de pesquisa que assina esta produção.

Os conteúdos expressivos desses interlocutores foram heuristicamente tratados como excertos de "mundos da vida" (life-worlds), fluxos de experiências corporais que devem ser compreendidos não apenas como narrativas objetivas sobre suas realidades, mas como experiências refletidas e significadas (SCHÜTZ; LUCKMANN, 1972; SCHÜTZ, 1979). O que acompanharemos com essas falas são como pistas para uma abordagem do fenômeno da insônia que foge e, muitas vezes, constrange a ansiedade clínica pela sua interpretação e "tratamento". Por essas falas, veremos que a ansiedade pelo desligamento ritual ou medicamentoso dos corpos insones pode encobrir uma ansiedade individual não facilmente declarada, aquela que faz desvelar um gestus quase político do sujeito, uma "pura medialidade" disposta entre a insatisfação diária do insone e o seu desejo intensivo de outra vida, de outras sensações e vivências que precisam de um par de olhos abertos e fitando um espaço ao final da jornada diária (AGAMBEN, 2008: 34).

O apuro dos diálogos que realizamos também nos inspira a qualificar o que chamamos de Corpo Insone (C.I.), categoria que advém da ideia de que esses 
mundos da vida são manifestados não apenas através das razões de um organismo contornado somente pela sua fala. Por meio do trabalho de pesquisa, aduzimos que o conteúdo da recursiva expressiva advém, antes, do próprio corpo e das suas razões sócio-psico-biológicas manifestadas (MAUSS, 2013: 422). Desse modo, quando entrevistamos sujeitos de experiências refletidas, encontramos também relatos de vivências corporais que nos davam pistas na direção da hipótese de que a insônia poderia ser um gestus ansioso não por um desligamento, mas pelo desparecimento de uma subjetividade obrigada pelo "saber dormir para melhor acordar e viver"; ou, como já tratava Zaratustra através da voz autoral de Nietzsche (2018: 18), "não é pouco saber dormir, para isso é preciso aprontar-se durante o dia".

\section{O Corpo Insone (C.I.): dispositivo e gestus}

Como todo dispositivo, o Corpo Insone (C.I.) é uma existência corporal física e de ideias pervasivo e abundantemente disputado. Por ele, falam corpos clínicos, terapeutas, vertedores de opiniões publicadas em periódicos, noticiários e livros de grande vendagem. Como se verá mais à frente, também por ele discursam as pessoas em seus atos intensivos de reflexão sobre elas mesmas, suas experiências de vigília.

No geral, a insônia parece se apresentar como um dispositivo com um expressivo potencial de detonar figuras da "ipseidade" humana, ações de individualização de mim a partir do meu distanciamento de um "inconsciente cósmico coletivo" feito de contatos do self com o mundo, produzindo aquele estranhamento que "me permite (para a consciência que faço de mim) que eu seja eu, e não outro" (RIBEIRO, 2005: 74). Nesse sentido, a insônia coloca as pessoas a pensarem sobre seus corpos inquietos, ansiosos, a rastrearem as disposições existenciais que os despertam e, a partir de então, a produzirem um disciplinamento feito da guia de muitos conhecimentos que tentam conhecer etiologias e ministrar tratamentos para essas individualidades que não conseguem se desligar.

Por vezes, do Corpo Insone (C. I.) são emuladas demandas que surgem, aparentemente, como forças muito singularizantes e individualizantes, o que coloca a vivência física e reflexiva da insônia como um fenômeno através do qual, pela individuação realizada como "forma social" (SIMMEL, 2006), o insone se amolda enquanto indivíduo (MATEUS, 2011): sob os efeitos de um corpo desafiado pela noite em claro, ele consegue dissertar sobre sua trajetória diurna, acredita conseguir discernir os fatores, erros e condições que teriam lhe impedido o desligamento, e, se servindo de tais movimentos, busca ajuda com base em uma aparente consciência da ipseidade, de cujo centro do argumento clínico é o seu próprio corpo individuado e pensado.

Por ser esse complexo de investimentos feito das pessoas sobre elas mesmas (ipseidade) e delas na direção de épistêmes de controle de condições clínicas e terapêuticas, concluímos que o C. I. e o fenômeno mais geral da insônia parecem se figurar, antes, como dispositivos:

\footnotetext{
qualquer coisa que tenha de algum modo a capacidade de capturar, orientar, determinar, interceptar, modelar, controlar e assegurar os gestos, as condutas, as opiniões e dos discursos dos seres vivos. (AGAMBEN, 2009: 40)
}

Desse modo, qualificar a insônia, atribuindo a ela um valor nosológico discernível nos coloca em diante de políticas da subjetividade. A clara referência de inspiração que atilamos é, sim, o projeto intelectual foucaultiano. Chamamos 
atenção que são dois os lugares dentro de tal projeto com os quais tentamos consolidar nosso diálogo. Um é aquele que abre à consideração da formação dos campos epistemológicos e do princípio da arqueologia das ideias, algo que tem expressão, entre outros lugares, no conteúdo por trás do título Les mots et les chose (1996):

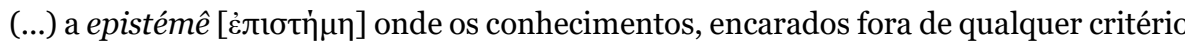
referente a seu valor racional ou a suas formas objetivas, enraízam sua positividade e manifestam assim uma história que não é a de sua perfeição crescente, mas, antes, a de suas condições de possibilidade; neste relato, o que deve aparecer são, no espaço do saber, as configurações que deram lugar às formas diversas do conhecimento empírico. Mais que de uma história no sentido tradicional da palavra, trata-se de uma "arqueologia”. (FOUCAULT, 1966: 13, tradução nossa)
\end{abstract}

O outro lugar de tal projeto com o qual formamos um par dialogante é aquele

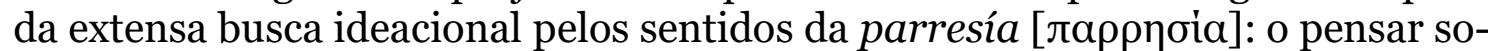
bre si mesmo para melhorar governar a si e aos outros que inspiram as tecnologias do "falar a verdade". O termo conceitual le dire-vrai (parresía) é empregado na investigação das modalidades e técnicas das relações dos sujeitos no governo deles e dos outros. Lembrando que, para tal argumento, "governo" é menos uma instituição político-territorial, e mais um plano micropolítico relacional e diádico de interações efetivadas com base em esteios epistêmicos. Assim, explica que

\footnotetext{
ao colocar a questão do governo de si e dos outros, gostaria de procurar ver como o "dizer-a-verdade" (le dire-vrai), a obrigação e a possibilidade de dizer a verdade nos procedimentos de governo podem mostrar de que modo o indivíduo se constitui como sujeito na relação consigo e na relação com os outros. O dizer-a-verdade, nos procedimentos de governo e na constituição de [um] indivíduo como sujeito para si mesmo e para os outros. (FOUCAULT, 2010: 42, tradução nossa)
}

O desenvolvimento conceitual do le dire-vrai é apresentado por Foucault ao longo de ao menos três títulos: L'Herméneutique du Sujet (1981-1982), Les Gouvernement de Soi e des Autres: cours au Collège de France (1982-1983) e La Courage de la Vérité: cours au Collège de France (1983-1984). Para nós, tal noção é aproveitada pelo seu potencial de pensar como os mecanismos clínicos previstos pelas epistemes do sono incentivam o reforço de uma positividade medicamentosa e terapêutica que lê no indivíduo e na sua capacidade de se autodisciplinar através de falas e gestos de consciência a possibilidade de conquista do desligamento noturno, enfim, da superação do estado de vigília causado pela insônia. Assim, ao Corpo Insone (C. I.) é ensinado que "se desligar de aparelhos eletrônicos antes de ir para a cama”, "esvaziar-se através de condutas meditativas" e "evitar alimentos energizantes e estimulantes" ao final do dia são atitudes que concorrem ao sucesso de uma noite de sono satisfatória.

Menos do que um ato estrito de fala, o "dizer a verdade", a parresía, significa uma assunção consciente para si e para um outro consultante - a exemplo dos psicólogos do sono que compõem o corpo clínico do Instituto do Sono, por exemplo - de que minhas condutas de vida, meu disciplinamento, minhas escolhas e inciativas muito pessoais (essas geralmente relacionados aos hábitos diurnos do trabalho e dos relacionamentos) não têm feito de mim um bom "governante do meu próprio corpo". E como não me governo adequadamente, não me conheço, não sei dos meus limites e capacidades, e por isso também não posso governar os outros; em tese, não exerço bem as funções cíveis delegadas a mim durante o dia claro, principalmente aquelas impostas pela vida social do trabalho e de todos os predicados comuns à pessoa pública. 
O insone é, portanto, alguém a quem as clínicas incentivam a falar, a assumir e a exercer cuidados, tendo como centro disciplinar as próprias condutas de um corpo e a consciência sobre ele em sua relação reflexa. Controle dos hábitos desejosos relacionados à alimentação e à busca por fruição noturna são, por exemplo, mecanizados ao objetivo de instilar tal consciência concentrada sobre si, gesto de saber localizar condutas perversas ao sono e a corrigir biomecânica e ergometricamente tais disposições. Em seu célebre Assim falou Zaratustra, como um Sócrates que faz de nós leitores seu Alcebíades ${ }^{5}$, o sábio já avisava que "não é pouco saber dormir, para isso é preciso aprontar-se durante o dia” (NIETZSCHE, 2018 [1883-1891]: 18); dizendo mais:

Honrai o sono e respeitai-o! É isso o principal. E fugi de todos os que dormem mal e estão acordados de noite. O próprio ladrão se envergonha em presença do sono. Sempre vagueia silencioso durante a noite: mas o relento é insolente.

Ferindo a persecução obrigatória do sono, sua honraria ao corpo, o insone é comparável ao ladrão que "sempre vagueia no silêncio durante a noite: mas o relento é insolente". Seu estado descompensado pela falta de descanso o coloca como um corpo negligente, quando na vivência do estado pleno e obrigatório de vigília. Não vive, não se governa, nem governa bem aquele que não dorme, avisa Zaratustra e, em coro com ele, as épistêmes do sono.

Mas por que, hoje à noite, um corpo não quer ser desligado? Ao insone devemos reportar a pergunta. Porém, sabe-se do risco de essa inquisição assim formulada sobre a obrigatoriedade do sono parecer, mais uma vez, um "dizer a verdade" que surja como o reforço de uma positividade clínica ansiosa por corpos que se desliguem automaticamente. Por isso, em escapatória dessa óbvia parresía, nossa pergunta prioritária em diante de três interlocutores e dos seus corpos insones não foi baseada em um "por que não dormir?", mas, sim, em um "que outras coisas são procuradas e feitas por um corpo que não deixa ser facilmente desligado?”.

Fora dos mecanismos do "dizer a verdade" que escrutinam por individualidades aparentemente negligentes consigo mesmas, o que nos resta é compreender os "mundos da vida" feitos de províncias de significado finito (SCHÜTZ; LUCKMANN, 1972; SCHÜTZ, 1979; VAZ et al, 2013) que todo corpo insone produz sobre ele mesmo através de uma existência articulada por expressividades não pressionadas a confessar, mas a tentar significar suas volições vigilantes, seus hábitos de corpos insones. Por "mundos da vida" (life-worlds), compreendemos, em reproduzindo Alfred Schütz:

a esfera total das experiências de um indivíduo, a qual é delimitada pelos objetos, pes-
soas e eventos encontrados na busca dos objetivos pragmáticos do viver. É um 'mundo'
em que a pessoa está "totalmente alerta" e que se afirma como a "principal realidade"
da vida dela. (SCHÜTZ, 1979: 314)

É pelo delineamento dos mundos de pessoas que "estão totalmente em alerta" e em reconhecimento dos seus desejos de corpos despertos que apresentamos os excertos de falas de três narrativas biográficas insones. Na nossa compreensão, o corpo processa algo mais que ansiedade, frustração e insegurança em diante da insônia. Na sua impossibilidade de ser desligado automaticamente, ele manifesta uma certa consciência ativa de gestos de "desejos impredicantes" - isto é, um “desejo como empuxo em direção ao que não se determina por completo" (SAFA-

5 Os diálogos mantidos entre Sócrates (o mestre) e Alcebíades (o discípulo) são abundantemente explorados por Foucault no objetivo de descrever a arqueologia dos sabres envolvidos com a parresía o "dizer a verdade" (PLATÃO, 2016). 
TLE, 2015: 17) -, que, como relatam as falas, são feitos de percepções de incompletude, essas que por sua vez buscam realizações nas "saídas lúdicas" (LE BRETON, 2018: 13) feitas das sessões noturnas de cinema, do sexo buscado na madrugada e da compulsão alimentar, por exemplo.

Pelas falas que exporemos, o situ desejante deixa de ser o território do sono prescritivo, e passa a ser a própria insônia; realidade essa que nos auxiliou a proceder com a seguinte pergunta: é possível determinar a coisa ou, no mínimo, a aisthesis (a sensação) daquilo que tanto desejamos, e que nos impõe inquietude noturna, sentimento de que, como narra um dos interlocutores, "parece que o dia não acabou"? A insônia é só feita de condutas negativas ansiosas que precisam ser medicadas com positividades químicas e biomecânicas disciplinares? Para o avanço dessa segunda questão, perceberemos que se o sono é um dispositivo essa instituição explorada por muitas epistèmes, capturada em seu valor naturalizado e forçosamente presenteada ao insone como resposta aos seus problemas -, a insônia, por outro lado, é como um gestus quase que político de "desaparecer de si" do indivíduo. O que leva o nome de gestus compreende "a exibição de uma medialidade, o tornar visível um meio como tal (...) gesto como movimento que tem em si mesmo o seu fim (por exemplo, a dança como dimensão estética)" (AGAMBEN, 2008: 13).

Mas em que medida esse gestus da insistência corporal pela insônia, movimento não funcionalmente objetificado de se manter acordado, exemplificaria aquilo que David Le Breton chamou de "desparecer de si”? Segundo Le Breton, as buscas individuais por "desparecimentos" viriam, por um lado, da anunciada crise das identidades (GAUCHET, 2004) e, por outro, da tentação à individuação como relaxamento ante as obrigações prescritas por noções de sujeitos e subjetividades de desempenho (HAN, 2015):

\footnotetext{
Mesmo quando nenhuma dificuldade pesa, pode emergir a tentação de desligar-se de si mesmo - nem que seja por algum tempo - para fugir das rotinas e preocupações. Qualquer desobrigação é bem-vinda, ela permite desapegar-se por um instante. (LE BRETON, 2008: 10)
}

Ora, se o sono é a prescrição gestual determinada a fazer levantar saudável o corpo da vigília, daquele mundo da realidade cotidiana dentro do qual somos chamados a operar uma identidade (principalmente aquelas laborais), então a insônia, seus gestus, é como um abrir-se "a um afeto que me despossui dos predicados (sociais) que me identificam" (SAFATLE, 2015:12). Na insônia, há um corpo fora do predicado salutar do bem-acordar, levantar e se associar comunitariamente com a cidade, com o grupo, enfim, com os outros. Na insônia, como veremos, antes de nos desligarmos, nós desaparecemos para o mundo, enquanto gestualizamos alguns pequenos desejos impredicantes para o nosso "corpo político produzido pelo desamparo".

Um corpo político produzido pelo desamparo é um corpo em contínua despossessão e
desidentificação de suas determinações. Corpo sem eu comum e unicidade, atraves-
sado por antagonismos e marcado por contingências que desorganizam normativida-
des impulsionando as formas em direção a situações impredicadas. (SAFATLE, 2015:
12)

Aqui, precisamos jogar contraintuitivamente com a ideia clássica de que é antes o sono, e não a insônia, o pasto ideal para os desaparecimentos pela opção dos imaginários, das ideações e dos oníricos (IBN KALTHUN, 1958 [1377]; MARTINS, 1996; FREUD, 2018). De certo modo, é na insônia onde também conseguimos aduzir gestualidades na direção de outras experiências e significações para 
mundos possíveis. De um modo radical, os poetas e romancistas temáticos e viventes da insônia, a exemplo de Álvaro de Campos (um dos pseudônimos de Fernando Pessoa), Virgínia Wolf, Graciliano Ramos, entre outros, já nos avisaram sobre a imagem desse "grande sono em toda a cabeça e em cima dos olhos e na alma!" (PESSOA, 2007: 244). Não por acaso, Graciliano, Álvaro e Virgínia serão também os pseudônimos dos interlocutores de expressões expostas nos momentos seguintes do texto, acreditando que há, sim, uma “poesia a se dizer” por trás da insônia como mundo da vida refletido por esses homens e mulheres do cotidiano das cidades.

\section{A biomecanização do corpo insone}

Longe de produzirmos uma arqueologia das ideias ocidentais em torno do tema do tratamento dos distúrbios do sono, o que intentamos nesse primeiro momento é a descrição de algumas redes atuais de conhecimento feitas de especialistas e procedimentos que circunscrevem e definem o problema da insônia dentro de certas "condições de possibilidades" epistêmicas de tratamento (FOUCAULT, 1966: 13).

No Brasil, duas instituições têm ganhando notabilidade pela produção de conhecimentos clínicos relativos ao assunto: o Laboratório do Sono da Universidade de São Paulo (Incor/USP) e o Instituto do Sono, ambos sediados na cidade de São Paulo.

O Laboratório do Sono funciona no Instituto do Coração (Incor) do Hospital das Clínicas (HC) da Faculdade de Medicina da USP (FMUSP). O perfil de suas produções acerca pesquisas em torno do tratamento da "apneia obstrutiva do sono" (Obstructive Sleep Apnea - OSA) e do "ronco". Dessa instituição, destacase o caráter multidisciplinar das atividades de pesquisa, bem como o massivo incentivo à promoção de tecnologias de aferição de resultados e à testagem de procedimentos terapêuticos com grupos de pacientes. Um exemplo dessas qualidades aparece em duas das suas produções recentes. Uma delas publicada em artigo de título "Effects of Oropharyngeal Exercises on Snoring" (IETO et ali, 2015). A técnica do Incor foi testada com um grupo de 39 pacientes adultos de 20 a 65 anos, de ambos os sexos, todos com queixa de ronco. O conjunto de procedimentos oferecidos à resolução da OSA foi chamado de "oropharyngeal exercises" (exercícios orofaríngeos), que incentiva os seguintes procedimentos de um tratamento antirronco:

(1) empurre a ponta da língua contra o palato duro e deslize a língua para trás (20
vezes); (2) sugue a língua para cima contra o palato, pressionando toda a língua contra
o palato (20 vezes); (3) force a parte de trás da língua contra o assoalho da boca en-
quanto mantém a ponta da língua em contato com os dentes incisivos inferiores (20
vezes); (4) elevação do suave palato e úvula enquanto intermitentemente diz a vogal
"A" (20 vezes). Depois de obter o controle e a coordenação do movimento (geralmente
após 3-5 semanas), a elevação do palato mole e da úvula foi realizada sem vocalização
por 5 segundos; (5) recrutamento do músculo bucinador contra o dedo que é introdu-
zido na cavidade oral, pressionando o músculo bucinador para fora (10 vezes de cada
lado); (6) mastigaçãa bilateral alternada e deglutição usando a língua no palato, sem
contração perioral, sempre que se alimentar. (IETO et al., 2015: 685, tradução nossa)

Como meio de aferição dos resultados do tratamento, o mesmo Laboratório produziu um conjunto de estudos a fim de medir o efeito sonoro de pacientes que sofrem com o ronco resultante da Obstructive Sleep Apnea (OSA). Os resultados e objetivos dessa segunda pesquisa - que foi desenvolvida com membros do Instituto de Física (IF) da USP - foram assim anunciados: 
No presente estudo, propomos um método simples e preciso para identificar a OSA com base nos intervalos de tempo entre os eventos de ressonar e o número médio de eventos de ressonar por unidade de tempo, conforme revelado pela intensidade do som. Nosso método de analisar o ronco se correlacionou notavelmente bem com o AHI (Apnea Hypopneia Index) derivado da polissonografia, que é o outro método padrão para o diagnóstico de OSA. Além disso, um classificador automatizado baseado na análise R / S das intensidades do ronco foi capaz de identificar corretamente pacientes com AOS moderada a grave. (ALENCAR et ali, 2013: 276, nossa tradução)

Entre o método de testagem da OSA e a promoção da terapia dos "oropharyngeal exercises" (exercício orofaríngeos) vê-se a formação de uma complexidade clínica que é multidisciplinar em seus esforços de estabilização de condutas terapêuticas. Ações que visam encerrar os fatores patológicos dos distúrbios com o sono dentro de um quadro heurístico total que investiga, cria métodos baseados em aproximações de searas epistemológicas distintas, aplica-os e afere resultados; princípios que visam reforçar a extensão de um paradigma de conhecimento alternativo em diante dos anteriores (KUHN, 2013[1962]). Perceber que o método apresentado pelo artigo de excerto citado acima foi pensado para se relacionar e ampliar os resultados já fornecidos pelo método anterior, aquele de nome Apnea Hypopneia Index (AHI).

Embora a apneia e o ronco em geral promovam, via de regra, apenas intervalos no contínuo da experiência noturna de sono - ou seja, sejam de forma escalar diferentes da insônia -, o que envolve as ansiedades médicas em torno do tratamento desses distúrbios tem a mesma origem na busca pela resolução dos "distúrbios do sono": a perseguição do controle das condições que afetam sujeitos e subjetividades de desempenho que apresentam sonolência durante o dia, queda no rendimento intelectual e laboral, irritação e cansaço. Nesse sentido, a apneia, o simples ronco (fora do quadro patológico da OSA) e a insônia se correlacionam desde que expressam as irregularidades que evitam que o sono, como dispositivo, se realize segundo uma prescrição social e clinicamente ideal. Como indica o conceito mais geral para a insônia fornecido pelo Instituto do Sono, esse é um distúrbio a ser rastreado em suas vastas consequências:

A insônia se caracteriza por dificuldade em iniciar o sono, ou por acordar durante a noite com dificuldade para voltar a dormir com consequências no dia seguinte. Muitas vezes, ocorre a sensação de sono não reparador, de má qualidade, com cansaço diurno. Outras consequências da insônia em longo prazo são irritação, dificuldade para se concentrar ou de memória, sintomas de depressão, entre outras ${ }^{6}$.

Para a maioria dos tratamentos, o corpo em sua conformação orgânica é a unidade a ser reparada em sua feição anatômica e fisiológica natural - como no caso do tratamento da apneia por meio das etapas dos exercícios orofaríngeos e na sua feição deontológica (ou moral) e habitual, no caso do conjunto das observações que ilustram os procedimentos chamados de "higiene do sono".

Em sua página principal, uma conhecida indústria multinacional farmacêutica brasileira promove a campanha de título "Insônia: feche os olhos por essa causa". No vídeo promocional, ela convoca a população a observar seus cuidados com o sono e a consultar o médico em diante da recorrência do problema da insônia. Nas imagens, uma personagem sofre com os inúmeros barulhos que perturbam sua madrugada de sono, fazendo uma pequena coleção de sons que lhe acompanham durante a noite: são vizinhos que abrem chuveiros e portas, pessoas que caminham sobre o piso superior, cães que latem, entre outros. Em um site destinado ao assunto, a mesma empresa disponibiliza uma aba que chama de "hi- 
giene do sono", onde detalha o que trata como um conjunto de "intervenções psicoeducacionais" que visam alertar para os fatores externos que perturbariam a correta rotina do sono: praticar atividade físicas, criar ambientes relaxantes, evitar alimentos estimulantes antes de dormir são algumas das atenções profiláticas.

Também é com base na busca do que chama de o "sono normal" que a segunda instituição considerada pelo nosso estudo se baseia. Como organização privada, o Instituto do Sono é uma das muitas empresas que vêm capacitando corpos clínicos destinados à pesquisa e ao tratamento da insônia. Seus profissionais advêm das especialidades da chamada Medicina do Sono - neurologistas, neurofisiologistas, otorrinolaringologistas, pneumologistas, entre outros -, além de psicólogos, biólogos, biomédicos, dentistas, assistentes sociais, fisioterapeutas, educadores físicos e pesquisadores em geral. Atendimento clínico, promoção de cursos para profissionais da área e projetos de pesquisa são os três campos de atuação empresarial do segmento.

Um dos projetos de pesquisa tocados pelo Instituto do Sono se chama EPISONO, e visa promover um amplo rastreamento da qualidade do sono da população da cidade de São Paulo. No seu painel de divulgação, os coordenadores informam que o objetivo prioritário da iniciativa é "fornecer importantes dados para a evolução científica sobre distúrbios do sono, bem como melhorar a qualidade de vida da população, influenciando, inclusive, na formação de políticas públicas sobre o tema" . Em outra das suas publicações, a empresa divulga o que trata como sendo algumas "dicas para preservar o sono":

\begin{abstract}
Ter horários regulares para dormir e despertar; ter um ambiente de dormir adequado: limpo, escuro, sem ruídos e confortável; não fazer uso de álcool ou café, determinados chás e refrigerantes próximo ao horário de dormir; jantar moderadamente em horário regular e adequado; não levar problemas para a cama; realizar atividades repousantes e relaxantes preparatórias para o sono; ser ativo física e mentalmente ${ }^{8}$.
\end{abstract}

Entre outras, essas são algumas das ações que visam reconhecer os limites do corpo insone. Assim como as inúmeras publicações que incentivam as mesmas atitudes - como visto anteriormente -, o centro do cuidado reside sobre o próprio indivíduo e suas maneiras de psicoeducar biomecanicamente suas atitudes, inclusive os desejos que aparentemente sinalizariam ansiedades ou apenas hábitos "inadequados" à fisiologia do corpo do horário noturno, a exemplo do consumo de alimentos e bebidas em excesso ou que tenham composições estimulantes. É o indivíduo em sua vigilância que é chamado a manter responsabilidade sobre o seu corpo insone, promovendo como que um reforço da ordem das obrigações que lhe ocorrem durante a jornada diurna.

Seja na instituição especializada no desenvolvimento de implementos técnicos e terapêuticos específicos - como é o caso do Laboratório do Sono (Incor/USP) -, seja na instituição privada de estrutura organizacional e profissional mais abrangente, o que se incentiva é uma épistême do sono baseada na apropriação holística de procedimentos de cuidado com fatores biológicos e a divulgação de conhecimentos profissionais e aconselhamentos na forma de consultas, cursos e notícias. Para todas essas instituições, as medidas de tratamento da insônia envolvem um complexo feito de intervenções medicamentosas e medidas comportamentais e cognitivas instigadas no indivíduo.

Quando a insônia é descrita em sua multicausalidade pelo Instituto do Sono, por exemplo - assinalando "problemas psiquiátricos como ansiedade, depressão,

7 cf. Projeto EPISONO. Disponível em: https://www.sono.org.br/institucional/noticias.php. Consultado em: 13 de agosto de 2019.

${ }^{8}$ cf. Sono. Disponível em: https://www.sono.org.br/sono/index.php. Consultado em: 13 de agosto de 2019. 
uso de alguns medicamentos em longo prazo e de bebida alcoólica; no último caso, principalmente após a suspensão do consumo" ${ }^{-}$, o que parece se atualizar é a figura do "nervoso" (DUARTE, 1986). Para esse sujeito, as inciativas públicas e privadas inauguram um complexo argumentativo e de intervenções sobre um distúrbio para o qual, mais do que para outras patologias da sociedade moderna do cansaço, o que é discernido é um corpo e suas doenças como uma realidade sócio-psico-biológica manifestada (MAUSS, 2013: 422); como se a insônia estivesse a multidimensionar a Medicina tradicional, ainda que essa ainda se apresente muito biologicamente determinante em seus procedimentos.

A outra diferença das leituras médicas da insônia é que a abordagem da realidade desse distúrbio é feita, em grande medida, por esforços de individuação dos fatores de controle e cura dos males que afetam o sono. De um certo modo, a promoção de tecnologias de cuidado de si ilustradas pelas "higienes do sono" e pelos "exercícios orofaríngeos" nos projeta em retorno à asserção presente em Les techniques de soi (1982), quando o autor nos lembra que a máxima especificação do conhecimento médico tem na pragmática dos autocuidados dos corpos individuais o seu amplexo ideal:

\footnotetext{
O cuidado de si não é um outro tipo de pedagogia; este deve se tornar um cuidado médico permanente. O cuidado médico permanente é uma das principais características do cuidado de si. O indivíduo deve se tornar o médico de si. (FOUCAULT, 1982: 19, tradução nossa)
}

O que tentamos explorar através dos mundos da vida de três corpos insones que apresentaremos a seguir são as possibilidades de reconstrução do sentido da insônia não por essa via da expectativa dos seus dispositivos e das suas várias autoridades, mas, sim, pelo seu potencial de se manifestar como um gestus impredicante de "desaparecer de si" desse mesmo indivíduo-alvo (SAFATLE, 2018; LE BERTON, 2018; AGAMBEN, 2008). No geral, é contra o estatuto de normalidade e normatização biomecanizante do sono que alguns desses corpos insones falam pelas suas expressões.

\section{Os mundos da vida do Corpo Insone (C. I.)}

Percebemos que a pergunta não era "por que não dormir?”, mas, talvez, "por que não se desligar e o que fazer enquanto isso?”. Entre a primeira forma de indagar os corpos insones dos nossos três interlocutores e a segunda, veremos, na sequência, que se forma uma notável diferença entre uma antropologia pós-estruturalista das conformações de poder - principalmente de base micropolítica e uma "antropologia subtrativa" (SAFATLE, 2018; LE BRETON, 2018); sendo a última aquela que está no horizonte de divulgação conceitual que chaveia o tópico seguinte do nosso artigo.

Ele disse "eu posso falar com você, mas prefiro fazer isso por áudio (WhatsApp). Não queria pelo Skype!” Graciliano (nome fictício), 26 anos, estudante do curso de Administração de uma universidade pública de Minas Gerais, foi conhecido por nós dentro de grupos de frequentadores do Facebook que acompanhavam e divulgavam notícias relativas à Medicina do Sono. No nosso primeiro contato, depois de uma conversa prévia através da troca de mensagens, ele declarou: 
como tratamento, coisas do tipo. Eu ainda tenho insônia. Mas eu sinto que acompanhar esses assuntos me ajudou a ter mais cuidado comigo, com a minha rotina, sabe?, até com a forma como eu dormia. (Graciliano, nome fictício, 26 anos, contato 01 Gravação 01 [áudios do WhatsApp - tempos diversos], folhas transcritas 01-03, linhas acima transcritas 01-05)

A insônia era apresentada por Graciliano não na sua etiologia subjetiva, na investigação pessoal da razão causal para a sua recorrência desde a trajetória de um indivíduo. A primeira expressão, como aparece no excerto acima, era apenas a de que a insônia precisava, de alguma forma, ser sanada em seus efeitos. Para isso tinha que ser reconhecida nele próprio - como corpo consciente das possibilidades das tecnologias de cuidado disponíveis - e, em seguida, tratada pela correção de hábitos inadequados:

\begin{abstract}
Sabe essas ideias de você se preparar pra dormir: não tomar café horas antes do sono, dormir em um quarto com pouca luz, não ficar vendo coisas no celular, coisas que preocupam a gente? Isso tudo eu comecei a fazer, e eu vi que me ajudaram até um certo tempo. Mas parece, não sei, que eu tinha muitos problemas na época ou, então, aquelas ações, sabe?, começaram a ficar muito comuns pra mim, a não fazer sentido pras minhas necessidades. Eu desligava todas as luzes, fazia tudo certo, mas meu sono voltava a ficar "quebrado" daquele jeito com o tempo. Então eu saí fora daquela disciplina. (Graciliano, nome fictício, 26 anos, contato 01 - Gravação 01 [áudios do WhatsApp - tempos diversos], folhas transcritas 01-03, linhas acima transcritas 07-16)
\end{abstract}

Quando o os desafios transpuseram as condições de possibilidade para o tratamento do distúrbio - que, ao final, acabou não sendo resolvido pelas técnicas da "higiene do sono" -, também foram transformados os índices das leituras significativas das experiências vividas pelo corpo insone. Passava-se do corpo em sua rotina de admoestações biomecanizadas padrões ("procure dormir em horários fixos", "não coma isso ou aquilo", "criei um ambiente dessa maneira para o seu sono" etc.) para um outro dentro do qual era parcialmente aceita a sua impossibilidade de completo desligamento ritual.

\begin{abstract}
Então, tá, não conseguia dormir bem como eu queria! Encarei isso. Também não ia me medicar. Mas eu também não poderia ficar de um lado pro outro da casa sem fazer nada, aquilo que me adoecia, sabe? Eu tava no outro dia cansado porque não dormi e cansado porque ficava pra lá e pra cá dentro de casa, pensando em coisas pra fazer e sem fazer nada, claro! Aí eu... eu comecei a ficar no Tinder altas horas. Ficava ali. Ficava ali vendo e conversando com pessoas. Pessoal que claramente também sofria de insônia como eu, eu acho. E aquilo virou um hábito antes de dormir as poucas horas que eu conseguia dormir. Teve uma vez... uma, não... teve vez de tentar marcar algo com alguém altas horas. A gente se falou, ficou ali se falando e tal, e a gente decidiu se encontrar... Depois acabou não dando certo porque um não morava tão perto do outro como a gente imaginava e tava tarde, essas coisas (risos). (Graciliano, nome fictício, 26 anos, contato 01 - Gravação 01 [áudios do WhatsApp - tempos diversos], folhas transcritas 01-03, linhas acima transcritas 01-12)
\end{abstract}

Na mesma proporção que há uma assunção informada do corpo insone como um corpo indisciplinado, também é volitivo o gestus de aceitar a impossibilidade do desligamento e proceder com a busca ativa pelo preenchimento de um espaço de vontades insones, desejos que estão ali e que precisam de uma substância de significado.

Mas aquela história do Tinder também já ficou, sei lá, sem muito sentido. Não era bom. Eu me sentia parado demais ali, sem alternativa, só esperando dormir e com as mesmas conversas. Aí virou modinha aquelas academias de madrugada, e achei aquilo super legal. Daí decidi entrar numa dessas academias. Fazia meus exercícios, conversava um pouco com o pessoal de lá e quando chegava cansado em casa já ia dormir. E conseguia dormir bem. Ainda tava com problema de insônia? Tava! Mas tava fazendo alguma coisa. E isso de eu sair, ir pra algum lugar, de não ficar em casa 
sofrendo com aquilo, eu gostava. Eu podia curtir essa insônia porque eu alongava meu sono um pouco pela manhã. Mas aí mudou meus horários de estudo e de trabalho, e não pude mais continuar na academia. Não aproveitei mais. (Graciliano, nome fictício, 26 anos, contato 01 - Gravação 01 [áudios do WhatsApp - tempos diversos], folhas transcritas 01-03, linhas acima transcritas 01-11)

Quando se acomoda entre condições possíveis para a vivência de um estado produtivo de vigília, o corpo insone é, mais uma vez, protestado pelas razões muito corriqueiras que deflagram a sua existência: as mudanças das atividades do dia se chocam com a possibilidade de convivência com a insônia e com as mudanças dos horários do sono. O desempenhado demandado pela vida diurna cobra seu espaço entre a possível autonomia sobre "o que fazer com a minha noite e com a minha obrigação de dormir".

Na verdade, procurar conversar e encontrar pessoas na madrugada ou praticar exercícios físicos não parecem, segundo a expressão do interlocutor, simplesmente como medidas para "buscar o sono", nem são práticas referidas aos objetivos dirigidos àquilo que Agamben chamou de "facere" (o "agir com fim", segundo a semântica latina original do termo). São gestus, de acordo com o que entendemos, justamente porque são atitudes de uma pura medialidade que se interpõem entre o "não saber o que fazer com as minhas horas em claro" e o "empuxo ao movimento, ao sair de casa em prol de uma verdadeira vida ativa". Mas não aquela vida obrigada pelo calendário diurno, e sim aquela para o qual o sujeito de desempenho desaparece, já que é ele quem faz o seu horário de desligamento e de despertar, atribuindo outros sentidos mais pessoais aos mundos da sua vida em claro.

\begin{abstract}
Olha, manter essa mercearia me deixa cansadão, morto! Eu tô acabado, quando termina o dia! A-ca-ba-do! Atendendo o pessoal, indo buscar isso e aquilo, aguentando freguês, que às veze é bicho chato mesmo... Quando eu fecho aqui essas portas, eu penso "essa noite eu durmo bem! Essa noite eu durmo pra valer!". Mas não é isso que acontece. O certo era eu chegar em casa e ir dormir, não é, por que eu tô cansado, não tô? Mas não, não é assim! E isso me deixa muito intrigado. Como é que uma pessoa que tá cansada, com as pernas latejando de dor, joelho e isso e aquilo outro, e ele não consegue colocar a cabeça no travesseiro e dormir?! Parece que eu tô elétrico, parece que o dia não acabou pra mim. O corpo tá quente, aí ele não relaxa. Acho que é isso. Não sei. (Álvaro (nome fictício), 48 anos, contato 02 - Gravação 02 [26’ 46”], folhas transcritas 01-04, linhas acima transcritas 01-11)
\end{abstract}

Quem assim indaga é o interlocutor ao qual passamos a chamar de Álvaro, 48 anos, dono de uma mercearia de variedades alimentícias em um bairro popular da cidade de Teresina, Piauí; pessoa da qual podemos registrar a fala em presença física. Sua questão é uma "inquietação" em diante de um aparente ilogismo: por que o corpo cansado do dia não quer ser desligado durante a noite, quando tem oportunidade de fazê-lo?

A significação dada a esse corpo que ainda muito cansado não desliga chama atenção para o seu superaquecimento, como uma maquinaria que acabou de ser desligada e da qual algumas peças mecânicas continuam a girar por razão de uma inércia. Mas o inatural do gesto de não dormir vencido pelo estafo ainda se reveste de mais estranheza ante a narrativa de Álvaro sobre o seu corpo insone, organismo de movimento estático irrefreável:

O engraçado, eu vou já te dizer: é que eu aprendi a assistir o diabo de uns filme quando eu fecho aqui o comércio. Eu peguei e comecei a assistir uns filme fraco, parado. Mas eu gosto mesmo é de filme de ação. Eu gosto é de filme de guerra! Aqueles filme bom! Um dia eu assisti um aí de madrugada... como era o nome? Filme bom! $E$ eu gosto desses filme. E eu peguei essa mania de assistir o diabo desses filme na hora que é pra eu tá dormindo. Porque no outro dia eu tenho que acordar cedo, porque eu não abro o comércio de manhã, mas tenho outro emprego: eu instalo cerca elétrica. 
Mas aí é isso, eu só vou dormir já quase no meio do filme, e aí deixo uma parte pra depois. Às vezes assisto o filme inteiro porque tô sem sono mesmo. Aí abro uma cervejinha pra ver se ajuda e durmo. Mas é difícil. (Álvaro (nome fictício), 48 anos, contato 02 - Gravação 02 [26’46”], folhas transcritas 01-03, linhas acima transcritas 0111)

São signos paradoxais que despertam a inquietação de Álvaro e a nossa, em diante de suas expressões. Primeiro, os filmes que acalantam sua vontade não são aqueles dos gêneros "fracos, parados", talvez como os dramas ou os experimentos da prateleira de arte; pois esses não alentam o contentamento da sua insônia. Há uma escolha ativa e determinada do gênero que se quer ver. Não são títulos sedativos para dormir - porque, na verdade, alguma coisa não quer ser desligada -, são filmes para uma fruição final, choques neuronais feitos de estampidos de bombas, gemidos e euforias de uma brigada militar vitoriosa. Cinema para acompanhar um "corpo que tá quente”, ou para diante dele apresentar uma metáfora alternativa e mais feliz para a sua própria jornada. Não são roteiros como fármacos hipnoindutores, como os benzodiazepínicos ou compostos como trazodona, mirtazapina, doxepina e o conjunto de outros antipsicóticos sedativos para o tratamento da insônia crônica (POYARES et ali, 2005). São filmes para que o dia ainda seja lembrado não na memória dos músculos das pernas e dos braços, esses já macerados, mas na excitação do plexo cardíaco. O corpo insone de Álvaro parecer desejar um cinema que definitivamente vença por ele, através do qual ele próprio desapareça das obrigações do trabalho pela manhã.

Passamos a outra zona ativa de um corpo insone: o estômago. Quem fala das suas razões é chamada por nós de Virgínia, 38 anos, professora da rede pública de ensino básico do estado do Piauí, que assim descreve sua insônia:

\begin{abstract}
Eu ia dormir com uma fome, um vazio. Mas não era fome, porque eu comia bem e voltava pra cama, mas não conseguia dormir. Às vezes acordava $2 \mathrm{~h}$ da manhã e ia fazer algo pra comer, e não dormia mais. Aí eu disse "quer saber?! Vou tentar jantar mais tarde e jantar bem”. Eu sabia que isso não era certo, mas eu sentia essa fome e, mesmo assim, eu não engordo fácil. Não sei daqui pra frente (risos). Aí comecei a comer melhor antes de dormir. (Virgínia nome fictício, 38 anos, contato 03 - Gravação 03 [33' 9”], folhas transcritas 01-03, linhas acima transcritas 01-06)
\end{abstract}

No diálogo mantido com os pesquisadores, o centro da atenção da insônia não era feito dos olhos que não cerram, mas do barulhar do estômago, da ansiedade pelo alimento. O impeditivo para a "noite de sono adequada" aparentemente está no corpo que não consumiu uma base alimentar saciável. Mas falta uma lembrança sobre os efeitos desses estímulos, que será recobrada agora:

\begin{abstract}
Ah, e tem uma outra coisa: comendo às 2 h da madrugada ou comendo bem nojantar, eu sempre sonhava, eu sempre tinha pesadelos. Isso é muito comum pra mim. Eu não gosto de sonhar, mesmo quando é sonho bom. Acho que é porque a maioria dos sonhos são pesadelos pra mim, daí eu não gosto de sonhar com coisa nenhuma. E comer muito me faz ter uns sonhos esquisitos (risos). Já ouvi gente falar a mesma coisa. Aí sabe o que eu fiz? Ao invés de comer, eu passei a cozinhar de madrugada. Não tem esses programas de cozinha? Então, isso me incentivou a cozinhar mais. E eu aprendi que cozinhando, eu me satisfazia... era... era como se eu comesse ali, embora eu não comesse. Era só bom de fazer aquilo. Como era comida, eu levava aquela comida pro trabalho e distribuía entre os meus amigos, pra não se estragar em casa. Mas é isso, acho que não comia mesmo porque aquilo me dava uns sonhos. Eu não gosto de sonhar! Mexe demais com a minha cabeça (risos), passo o dia querendo entender aquilo, sofrendo com aquilo. E eu já tenho muita coisa pra me preocupar como professora. (Virgínia, nome fictício, 38 anos, contato 03 - Gravação 03 [33' 9"], folhas transcritas 01-03, linhas acima transcritas 01-15)
\end{abstract}

O gestus da insônia parece ser feito de um desvio que percorre entrechos como províncias físicas e simbólicas do próprio corpo. Se o córtex cerebral em 
alerta protagoniza as atividades diárias - para o caso de Virgínia, uma professora -, então o situ desejante noturno tem referência em outro lugar: é primeiro no estômago e depois na evolução braçal do preparo da comida. Como uma compensação que busca um equilíbrio interno das aisthesis (sensações) do corpo, o C. I. busca por aquilo que lhe foi obliterado, e que nem a vigília nem o sono e muito menos o sonho podem produzir uma reparação.

Virgínia é um corpo que não quer sonhar. Nem todos os corpos precisam sonhar como obra de desaparecer. Respondemos aqui a Ibn Khaldûn (c. 13321406), um dos primeiros filósofos sociais entre o Ocidente e o Oriente a enaltecer a obrigatoriedade salutar do par sono e sonho, dizendo:

A visão real do sonho é a consciência da alma racional na sua essência espiritual. A alma torna-se espiritual liberando-se das coisas corporais e das percepções corpóreas. Isso acontece por meio da agência do sono. (IBN KHALDUN, 1958 [c. 1377]: 46, tradução nossa)

Mas o sonho, tanto quanto o sono - essas duas entidades da mitológica helenística representadas por Hypnos e Morfeu -, também é um dispositivo, um rastreável, principalmente para o imaginário onírico das pessoas das metrópoles, como fez observar Martins (1996). Aliás, desligar-se não é desaparecer. Os que têm sono desligam-se, os insones desaparecem, deve explicar uma antropologia subtrativa.

\section{Uma antropologia subtrativa: em conclusão}

O Corpo Insone (C. I.) lida com duas feições emocionais: a percepção da despossessão do corpo das suas razões orgânicas e, em resposta a ela, o gestus que ousa superar a positividade do sono prescritivo através do instilar de desejos impredicantes.

Pela apreciação das falas, percebemos que uma antropologia que relate do corpo apenas sua "reprodução mimética que serve de palco para a produção e reprodução do poder" (STOLLER, 1995: 41, tradução nossa) não alcança o nível fora do padrão dos "agenciamentos coletivos de enunciação" (GUATARRI e ROLNIK, 1996: 31) em que o insone, por exemplo, é perfilado e autopromovido em sua individualidade massiva. Urge saber produzir detalhes etnográficos das formas instanciais como as experiências de vida se mostram entre gestos ativos de não negociação com enunciados e biomecânicas disciplinadoras; enfim, com a diversidade dos projetos da modernidade que faz do sofrimento um fixador de identidades sociais (HENRY, 2003).

Uma antropologia que se renove para além da simples verificação dos quadros de reprodução da vida social, e que ainda assim fale do centro dos jogos modulares entre emoções e instituições determinantes de poder, deve, no nosso entender, manter atenção ao que inspira uma "antropologia subtrativa":

\footnotetext{
Pode-se falar aqui em uma "antropologia subtrativa" porque se trata de fornecer a figura de um processo que não se esgota na atualização das formas de vida, formas que obedecem aos limites das condições de reprodução material próprias às sociedades contemporâneas. Por isso "subtrativa", pois marcada pelo impulso de um sujeito que se subtrai aos modos atuais de determinação e que procura fazer desse movimento de subtração a expressão do desafio levantado contra o limite dos mecanismos de reconhecimento social. (SAFATLE, 2018: 25)
}

Assim, para essa antropologia, o insone não pode mais ser descrito apenas como uma identidade sociopatologizante, nem tão somente como um marcador dos princípios políticos que arregimentam suas tecnologias de cuidado consigo 
mesmo. É preciso estar além da crítica pessimista e das leituras internas e originárias das instituições de poder.

Por isso, do contrário do reforço da descrição dos processos de "desligamento" de indivíduos pelo sono, o que procuramos valorizar foram as condutas de "desaparecimento" de sujeitos de desempenho dentro de corpos que cambiam o centro dos seus desejos: se o estudante tem na letargia dos hábitos virtuais de consumo o local de conformação do seu corpo em estado de vigília, o corpo insone procura nos músculos e no estímulo sexual o centro de um desejo renovado (falamos, aqui, de Graciliano); se a vida em claro é feita da mecânica repetitiva de músculos estafados, o corpo insone busca nos olhos e no plexo cardíaco um novo centro de uma experiência neuronal e emocional (tratamos, aqui, de Álvaro); e se, por sua vez, é o aparelho cognitivo que sofre uma sobrecarga de demandas ansiosas, é no estômago e nos braços em movimento que o corpo insone concentra sua expectativa de satisfação não óbvia (lembramos, aqui, de Virgínia). Registrar gestos de rejeição de desejos que medrem instâncias predicadas por estatutos de autoridades moral, política e juridicamente convenientes é, nesse sentido, produzir um projeto etnográfico para uma antropologia da subtração. A título do que fazer enxergar com essa antropologia, o que temos a dizer do Corpo Insone (C. I.), por exemplo, é que ele é todo aquele que sabe sumir com os predicados a si autoritariamente impingidos, e que também sabe se reinsurgir e reemergir com outros.

Recebido em 31 de agosto de 2019.

Aceito em 3 de janeiro de 2020.

\section{Referências}

AGAMBEN, Giorgio. Notas sobre o gesto [Tradução: Vinícius Nicastro Honesko]. Artefilosofia, 4 (1): 9-14, (1996) 2008.

AGAMBEN, Giorgio. O que é o contemporâneo? E outros ensaios [Tradução: Vinícius Nicastro Honesko]. Chapecó: Argos, 2009. pp. 77-92.

ALENCAR, A. M. et al. Dynamics of snoring sounds and its connection with obstructive sleep apnea. Physica A, 392: 271-277, 2013.

DUARTE, Luiz F. D. Da vida nervosa nas classes trabalhadoras urbanas. Rio de Janeiro: Jorge Zahar Editor/CNPq, 1986.

FOUCAULT, Michel. "Les techniques de soi". In : Dits et Ecrits. Tome IV, texte n. $363,1982$.

FOUCAULT, Michel. Les mots et le choses: une Archéologie des Sciences Humaines. Paris: Éditions Gallimard, 1966. 
FOUCAULT, Michel. L'herméneutique du sujet: cours au Collège de France (1981-1982). Paris: Gallimard le Seuil, 2001 [Tradução para o português: A hermenêutica do sujeito: curso no Collège de France. São Paulo: Martins Fontes, 2006].

FOUCAULT, Michel. O governo de si e dos outros: curso no Collège de France (1982-1983). São Paulo: Martins Fontes, 2010.

FREUD, Sigmmund. A interpretação dos sonhos [Tradução: Walderedo Ismael de Oliveira]. Rio de Janeiro: Nova Fronteira, 2018.

GAUCHET, M. Un monde désechanté? Ivry-sur-Seine: Édition D’Atelier, 2004.

GUATARRI, Félix; ROLNIK, Suely. Micropolítica: cartografias do desejo. Petrópolis: Vozes, 1996.

HAN, Byung-Chul. A sociedade do cansaço. Teresópolis: Vozes, 2015.

HENRY, Michel. "Souffrance et vie”. In : Phénoménologie de la vie I: de la phénoménologie. Paris: Presses Universitaires de France, 2003. pp. 143-156.

IETO, Vanessa et ali. Effects of oropharyngeal exercises on snoring. Chest (American College of Chest Physicians), 148: 683-691, 2015.

KHALDÛN, Ibn. Muqadimah (Prolegômenos, ou Filosofia Social) [Tradução: José Hhoury]. São Paulo: Safady, 1958 [1377].

KUHN, Thomas S. A estrutura das revoluções científicas. São Paulo: Perspectiva, 2013.

LE BRETON, David. Desaparecer de si: uma tentação contemporânea [Tradução: Francisco Morás]. Petrópolis: Vozes, 2018.

MARTINS, José de Souza. "A peleja da vida cotidiana em nosso imaginário onírico”. In: (Des)figurações: a vida cotidiana no imaginário onírico da metrópole. São Paulo: Editora Hucitec, 1996. pp. 11-46.

MATEUS, Samuel. O indivíduo pensado como forma de individuação. Estudos em Comunicação, 10: 93-1, 2011.

MAUSS, Marcel. "As técnicas do corpo". In: Sociologia e antropologia [Tradução: Paulo Neves]. São Paulo: Cosac \& Naify, 2013. pp. 329-422.

NIETZSCHE, Friedrich. Assim falou Zaratustra: um livro para todos e para ninguém [Tradução: Paulo César de Souza]. São Paulo: Companhia das Letras, 2018.

PEREC, Georges. Um homme qui dort. Paris: Denoël, 1967.

PESSOA, Fernando. Poesie di Álvaro de Campos [Tradução: Antonio Tabucchi]. Milano: Adelphe Edizioni, 2007.

PLATÃO, 428-347 a.C. O banquete (edição bilíngue grego-português). São Paulo: Editora 34, 2016.

POYARES, Dalva et ali. Sleep promoters and insomnia. Revista Brasileira de Psiquiatria, 27: 2-7, 2005.

RIBEIRO, J. P. Do self e da ipseidade: uma proposta conceitual em Gestalt-terapia. São Paulo: Summus Editorial, 2005.

SAFATLE, Vladimir. O circuito dos afetos: corpos políticos, desamparo e o fim do indivíduo. São Paulo: Cosac \& Naif, 2015. 
SAFATLE, Vladimir. "Introdução. Em direção a um novo modelo de crítica: as possibilidades de recuperação contemporânea do conceito de patologia social". In: SAFATLE, Vladimir et al (orgs.). Patologias do social: arqueologias do sofrimento psíquico. São Paulo: Autêntica, 2018. pp. 7-31.

SCHÜTZ, Alfred. Fenomenologia e relações sociais: textos escolhidos [Tradução: Ângela Melin]. Rio de Janeiro: Zahar Editores, 1979.

SCHÜTZ, Alfred; LUCKMANN, Thomas. The structures of the life-world (Tomo 1) [Tradução: Richard M. Zaner]. Heinemman/Londres: Northwestern University Press, 1973 .

SIMMEL, Georg. Questões fundamentais da sociologia: indivíduo e sociedade [Tradução: Pedro Caldas]. Rio de Janeiro: Jorge Zahar Ed., 2006.

STOLLER, Paul. Embodying colonial memories: spirit possessions, power and the Hauka in the West Africa. New York and London: Routledge, 1995.

VAZ, Paulo Bernardo Ferreira; COSTA, Débora Veríssimo. O choque e as províncias de significado finito de Alfred Schütz. Vozes \& Diálogo, 12 (2), 87-95, 2013. 


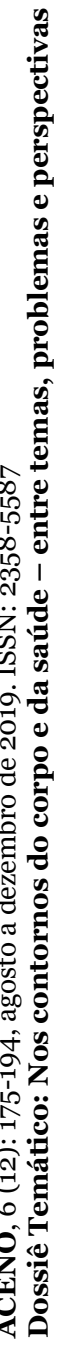

\section{Em branco}

